\title{
Effect of dimethyl fumarate on heme oxygenase-1 expression in experimental allergic encephalomyelitis in rats
}

\author{
Kaja Kasarełło ${ }^{1}$, Anika Jesion², Karolina Tyszkowska², Katarzyna Matusik², Katarzyna Czarzasta ${ }^{1}$, \\ Robert Wrzesień ${ }^{2}$, Agnieszka Cudnoch-Jedrzejewska ${ }^{1}$ \\ ${ }^{1}$ Department of Experimental and Clinical Physiology, Laboratory of Centre for Preclinical Research, Medical University of Warsaw, \\ ${ }^{2}$ Central Laboratory of Experimental Animals, Laboratory of Centre for Preclinical Research, Medical University of Warsaw, Poland
}

\begin{abstract}
Multiple sclerosis (MS) is an autoimmunological disease leading to neurodegeneration. The etiology of the disease remains unknown, which strongly impedes the development of effective therapy. Most MS treatments focus on modulating the activity of the immune system. Dimethyl fumarate (DMF) exerts a broad spectrum of action, such as modulating immune cell differentiation towards anti-inflammatory subtypes, influencing cytokine production, regulating immune cell migration into the central nervous system, and activating intracellular antioxidant mechanisms. It is well established that activation of the nuclear factor E2 (Nrf2)-dependent pathway, leading to expression of the second-phase antioxidant enzymes, is influenced by DMF.

In our experiments we used female Lewis rats in an animal model of MS - experimental allergic encephalomyelitis (EAE). The rats were fed with dimethyl fumarate to test the expression of heme oxygenase-1 (HO-1), one of the second-phase antioxidant enzymes, at specific time points of the symptomatic phases of the disease: on the first day

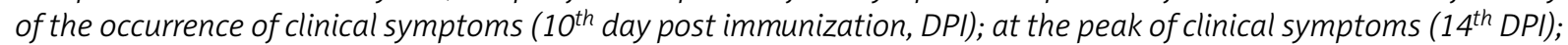
and at the end of the relapse (21 $\left.2{ }^{\text {st }} \mathrm{DPI}\right)$. The results showed that $\mathrm{HO}-1$ expression, at both the $\mathrm{MRNA}$ and protein level, is influenced by DMF administration only at the very beginning of the symptomatic phase of $E A E$, and not at the peak of clinical symptoms, nor at the end of the relapse. This indicates that the regulation of the Nrf2-dependent antioxidant pathway by DMF occurs at a certain time interval (early EAE/MS) and strongly underlines the importance of the earliest introduction of the therapy to the patient.
\end{abstract}

Key words: experimental allergic encephalomyelitis, dimethyl fumarate, heme oxygenase-1, antioxidant enzymes.

\section{Introduction}

Multiple sclerosis (MS) is an autoimmunological disease, where a chronic inflammatory state in the central nervous system (CNS), developed against myelin antigens, leads to demyelination and neurodegeneration [33]. The complexity and the high level of heterogeneity of the course of MS significantly impedes the understanding of the etiology of the disease and, consequently, impedes the development an effective pharmacotherapy [19]. The main goal in the treatment of MS is to inhibit the ongoing inflammatory process by general immunosuppression, such as by the intravenous administration of glucocorticoids during relapse. Many recent therapies target specific processes in the course of MS $[5,15]$. 
Dimethyl fumarate (DMF), successfully used for the treatment of another autoimmune disease, psoriasis, has recently been introduced as a therapy for MS. DMF has many advantages, such as an oral route of administration, a broad spectrum of immunomodulatory action, satisfactory effectiveness, and relatively mild side effects $[3,24,26]$.

In general, DMF is an anti-inflammatory agent with a broad spectrum of action. It has been shown that DMF causes: (i) the switching of the immune response from Th1-dependent to Th2-dependent [8], (ii) the differentiation of the dendritic cells into subtype II [11], (iii) an increase in anti-inflammatory cytokine production [8], (iv) a reduction in the number of circulating lymphocytes [13], (v) a reduction in macrophage and T cell infiltration into the CNS [2,3,32], (vi) the apoptosis of activated in vitro T cells [35].

In a series of investigations in cell cultures, it was observed that DMF is capable of activating the Nrf2 (nuclear factor E2) transcription factor, which is responsible for the regulation of the synthesis of the second phase antioxidant enzymes, such as heme oxygenase-1 (HO-1) and glutathione-S-transferase (GST), which scavenge the reactive oxygen species (ROS) $[3,14,37]$. In chronic inflammation there is prolonged reactive oxygen species production, which causes damage of the tissue surrounding the inflammatory site. Oxidative stress may be the major cause of neurodegeneration in MS [20,24]. Therefore, activation of the intracellular mechanism leading to the production of antioxidant enzymes is desired. Normally the activation of the Nrf2-dependent antioxidant pathway occurs during oxidative stress, and it is part of the cellular mechanism of defense against ROS. DMF activates the Nrf2-dependent pathway, probably in the same way as ROS [30,31], causing Nrf2 nuclear translocation, where it plays the role of a transcription factor for the second phase antioxidant enzyme genes $[4,9,14,17]$.

As the synthesis of the second phase antioxidant enzymes is one of the manifestations of Nrf2-dependent pathway activation, we investigated the expression of HO-1 at the mRNA and protein level during the symptomatic phase of experimental allergic encephalomyelitis (EAE) - an animal model of MS. We wanted to investigate whether the disease course is correlated with gene expression and changes in the protein levels. Next, we wanted to determine the influence of DMF administration, to rats with EAE, on the course of the disease at three time points: at the very beginning of the onset of symptoms, at the peak of symptoms, and at the end of relapse. Revealing the mechanism of the action of drugs changing the course of the disease may also provide new information about the disease pathomechanism. Here, it may provide information about the involvement of antioxidant mechanisms in both pathological and physiological processes occurring during the development of EAE.

\section{Material and methods}

\section{Animals}

The experiments were performed using female Lewis rats, weighing approximately $180 \mathrm{~g}$. The rats were obtained from the Animal House of the Mossakowski Medical Research Centre. The experiments were carried out with the consent of the Second Warsaw Local Ethics Committee (Act no. 64/2014).

\section{Experimental allergic encephalomyelitis induction}

On day 0 ( $0^{\text {th }} \mathrm{DPI}$ - day post immunization), the animals were subjected to anesthesia $(100 \mathrm{mg} / \mathrm{kg}$ ketamine $+1 \mathrm{mg} / \mathrm{kg}$ xylazine, intraperitoneal, Vetoquinol Biowet), and they were injected intradermally in the hind paws with an immunizing mixture $(100 \mu \mathrm{l}$ per paw). The mixture was prepared as follows: $50 \%$ guinea pig spinal cord homogenate in PBS (Merck Millipore) was mixed with Complete Freund's Adjuvant (DIFCO Laboratories) in the ratio $1: 1$, and supplemented with $4 \mathrm{mg} / 1 \mathrm{ml}$ Mycobacterium tuberculosis (DIFCO Laboratories). Healthy animals (without induced EAE) served as a control group.

\section{Dimethyl fumarate administration}

Beginning on the $3^{\text {rd }} \mathrm{DPI}$, the animals received dimethyl fumarate (Sigma-Aldrich), twice a day at a dose of $15 \mathrm{mg} / \mathrm{kg}$, intragastrically using a gauge-pointed needle, up to the day of animal euthanasia. DMF was suspended in $200 \mu$ l of vehicle $(0.8 \%$ methylcellulose, Sigma-Aldrich). The control animals received the vehicle alone.

\section{Clinical evaluation}

Every day the body mass of the rats was measured and the clinical symptoms were evaluated according to a 5-grade scale: 0 - no symptoms, 1 - limp tail, 2 - hind limb paresis, 3 - incontinence, paraplegia, 4 - quadriplegia, 5 - death [18]. 
The body mass ratio, as a ratio of the body mass on the $10^{\text {th }}, 14^{\text {th }}$ and $21^{\text {st }}$ DPI to the body mass on the day of immunization ( $\left.0^{\text {th }} \mathrm{DPI}\right)$, was calculated for every experimental group (mean for all animals in the group). The clinical symptoms of the animals were averaged within the groups (mean score) and counted for the time intervals: $10^{\text {th }}-14^{\text {th }} \mathrm{DPI}, 14^{\text {th }}-21^{\text {st }}$ DPI and $10^{\text {th }}-21^{\text {st }}$ DPI.

The animals were euthanized at three critical time points: on the $10^{\text {th }} \mathrm{DPI}$ - at the very beginning of the onset of clinical symptoms; on the $14^{\text {th }} \mathrm{DPI}$ - at the peak of clinical symptoms; on the $21^{\text {st }} \mathrm{DPI}-$ after the remission of the symptoms.

\section{Tissue collection}

At the end of the experiment the animals were sacrificed - rats were subjected to general anesthesia (100 mg/kg ketamine + $1 \mathrm{mg} / \mathrm{kg}$ xylazine, intraperitoneal, Vetoquinol Biowet), and bled. Brain samples were isolated and frozen rapidly in liquid nitrogen. All tissues were stored at $-80^{\circ} \mathrm{C}$ until the time of analysis.

\section{Heme oxygenase-1 protein level analysis}

To perform the analysis, brain homogenates were prepared as follows: the collected tissues were thawed, weighed, and the ice-cold PBS was added to obtain the final $20 \%$ homogenates. Steel beads were put into the tubes, and mechanical homogenization was performed at $50 \mathrm{~Hz}$ for 5 minutes (TissueLyser LT, Qiagen). Analysis of the HO-1 levels was performed with an ELISA (enzyme-linked immunosorbent assay) test (SunRed), according to the manufacturer's instructions.

\section{Heme oxygenase-1 mRNA expression level analysis}

Brain fragments were homogenized in Qiazol (QIAzol Lysis Reagent, Qiagen) and the total RNA was extracted using an RNeasy Mini Kit (Qiagen). The RNA concentration was estimated using a SmartSpec Plus Spectrophotometer (Bio-Rad). The RNA was used for multiplex real-time PCR reactions for the relative quantification of target genes of heme oxygenase-1 expression. Glyceraldehyde-3-phosphate dehydrogenase (GAPDH) was used as a housekeeping gene. Amplification of the mRNA of each gene was performed according to the Applied Biosystems protocols using the TaqMan RNA-to-Ct 1-Step Kit, the primer for the target gene (rat Hmox-1: Applied Biosystems, Rn00561387_m1) labeled with reporter FAM dye, the primer for the housekeeping gene (rat GADPH: Applied Biosystems) labeled with VIC dye, and the RNA template in RNase-Free Water (Eppendorf). The experiment was conducted using MicroAmp Optical 96-Well Reaction Plates with Barcode (Applied Biosystems). Amplification was performed in 40 cycles, at $95^{\circ} \mathrm{C}$ for 15 seconds and at $60^{\circ} \mathrm{C}$ for 1 minute, in a ViiA 7 Real-Time PCR System (Applied Biosystems). The relative gene expression was given on the basis of estimations of the values of the delta cycle threshold $(\Delta \mathrm{Ct})$ by relative quantification to the endogenous control.

\section{Statistical analysis}

All results are presented as mean \pm SD. Statistical assessments were performed using Student's t-test for independent samples using the STATISTICA software (version 13). The results were considered significant if $p<0.05$.

\section{Results \\ Body mass analysis}

The body mass of the animals was presented as the ratio of the body mass on the $10^{\text {th }}, 14^{\text {th }}$ and $21^{\text {st }}$ DPI to the body mass on the $0^{\text {th }}$ DPI. In our experiments we observed an increase of body mass in healthy animals (body mass ratio $>1$ ). EAE induction caused a significant drop in the body mass of the animals at all measured time points (Figs. 1A-C). There was a surprising further drop on the $14^{\text {th }}$ DPI in the body mass of the animals with EAE fed with DMF, in comparison with the EAE rats, and with the EAE rats fed with the vehicle (Fig. 1B). Feeding animals with DMF did not reverse the body mass drop caused by EAE induction (Figs. 1A-C).

\section{Mean score}

There were no significant differences in the mean score of the clinical symptoms observed in the animals between the groups during the presented time intervals (Figs. 2A-C). However, there was a visible tendency to decrease the mean score of symptoms in animals fed with DMF, compared with EAE non-fed rats for the time intervals $10^{\text {th }}$ to $14^{\text {th }}$ DPI (Fig. 2A), $14^{\text {th }}$ to $21^{\text {st }}$ DPI (Fig. 2B), and $10^{\text {th }}$ to $21^{\text {st }}$ (Fig. 2C). 

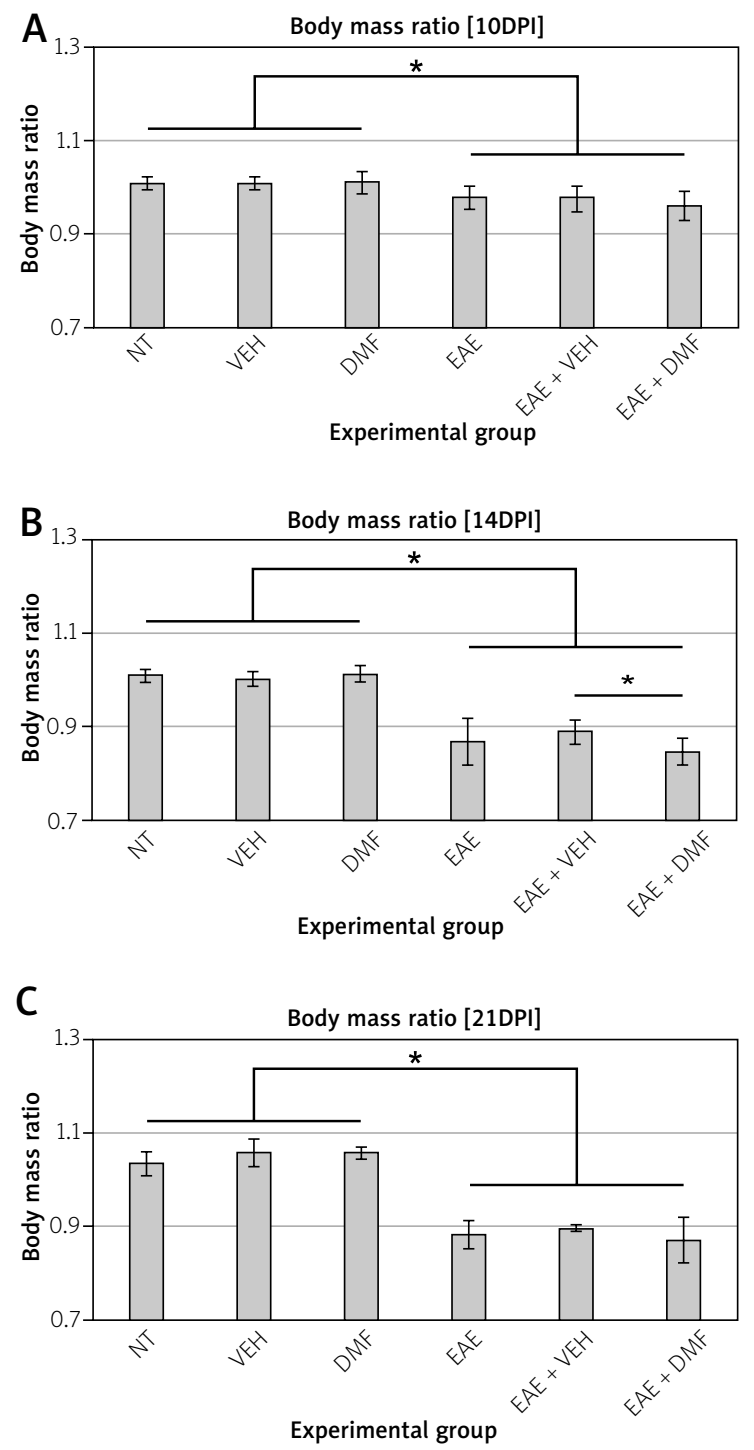

Fig. 1. Body mass ratio of rats on the: $10^{\text {th }}$ day post immunization (DPI) (A), $14^{\text {th }}$ DPI (B) and $21^{\text {st }} \mathrm{DPI}(\mathrm{C})$ in relation to the $0^{\text {th }} \mathrm{DPI}$ (taken as 1$)$. $n=6-10 .{ }^{*} p \leq 0.05$. NT - not-treated rats; VEH - healthy rats receiving vehicle; DMF - healthy rats receiving dimethyl fumarate; EAE - rats with experimental allergic encephalomyelitis induced; $E A E+V E H$ - rats with EAE induced, receiving vehicle; $E A E+D M F$ - rats with $E A E$ induced, receiving DMF.

\section{HO-1 protein level}

The analyzed HO-1 level in the brain homogenates differed significantly only on the $10^{\text {th }} \mathrm{DPI}$. There was an increase in the $\mathrm{HO}-1$ protein level in the brains collected from EAE animals fed with both
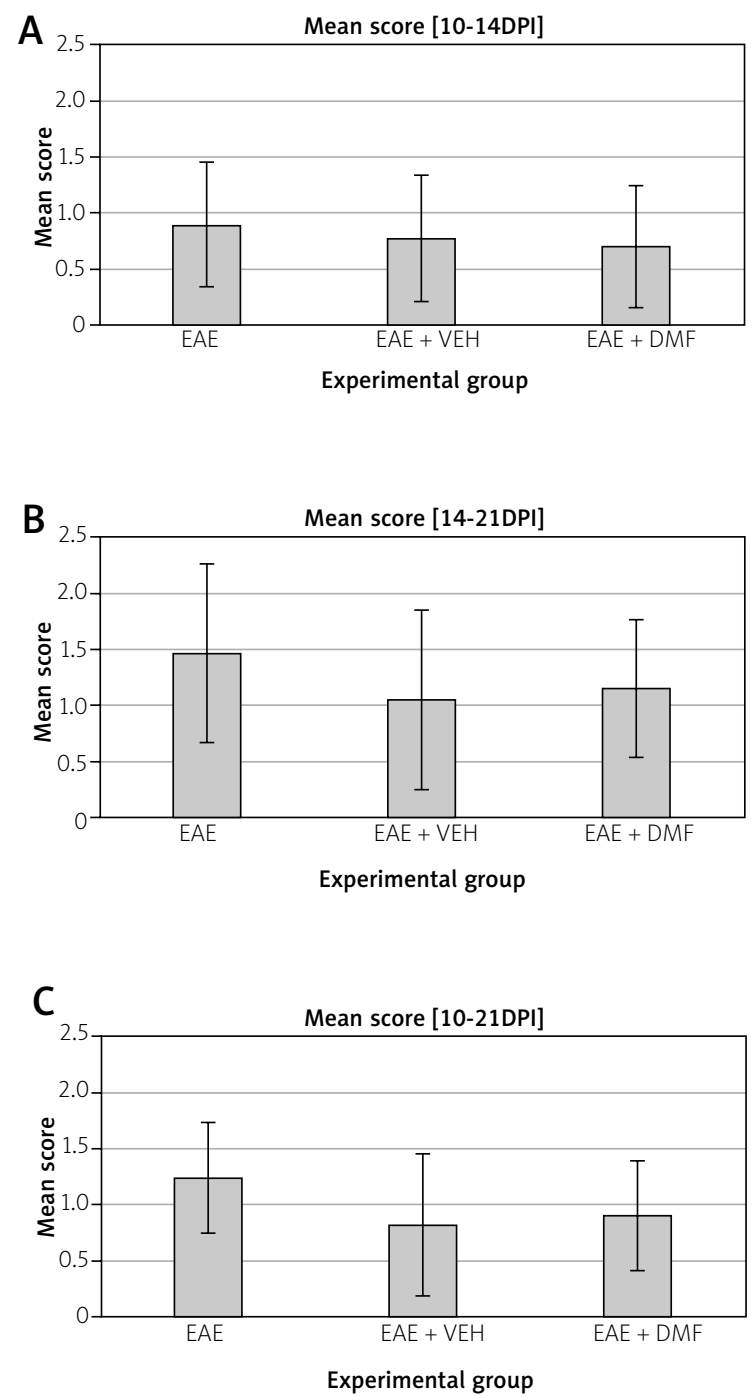

Fig. 2. Mean clinical score of animals counted for the time intervals: $10^{\text {th }}-14^{\text {th }}$ day post immunization (DPI) (A), $14^{\text {th }}-21^{\text {st }}$ DPI (B) and $10^{\text {th }}-21^{\text {st }}$ DPI (C). $n=6-10 .{ }^{*} p \leq 0.05$. NT - not-treated rats; VEH - healthy rats receiving vehicle; DMF - healthy rats receiving dimethyl fumarate; EAE - rats with experimental allergic encephalomyelitis induced; $\mathrm{EAE}+\mathrm{VEH}$ - rats with $\mathrm{EAE}$ induced, receiving vehicle; EAE + DMF - rats with EAE induced, receiving DMF.

vehicle and DMF in comparison with EAE non-fed rats (Fig. 3A). There were no significant differences between the HO-1 protein levels in tissues collected from rats on the $14^{\text {th }} \mathrm{DPI}$ (Fig. $3 \mathrm{~B}$ ) and the $21^{\text {st }} \mathrm{DPI}$ (Fig. 3C). 

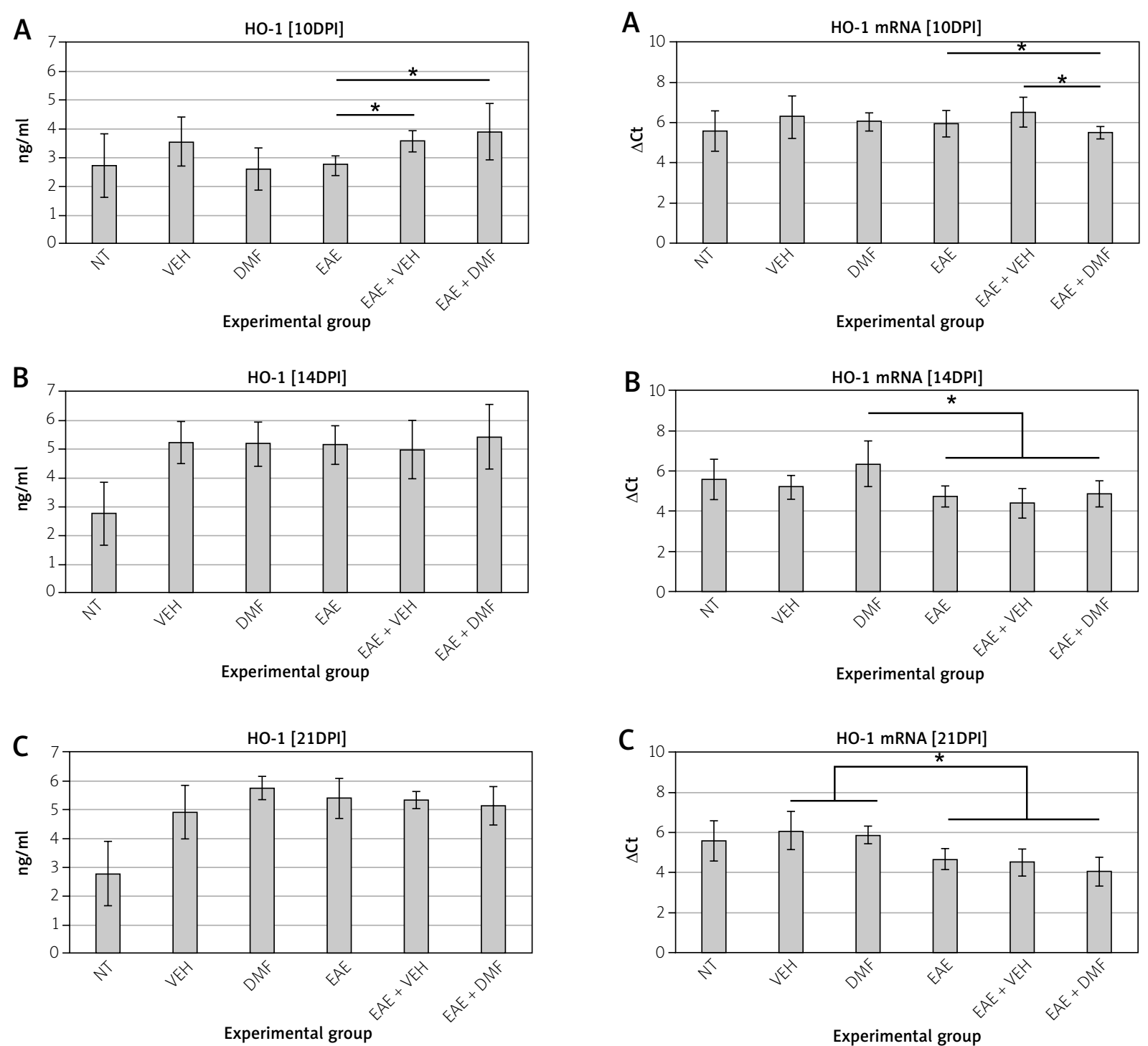

Fig. 3. Heme oxygenase-1 (HO-1) protein level in brains collected from rats on the: $10^{\text {th }}$ day post immunization (DPI) (A), $14^{\text {th }} \mathrm{DPI}(\mathrm{B})$ and $21^{\text {st }}$ DPI (C). $n=6-10 .{ }^{*} p \leq 0.05$. NT - not-treated rats; VEH - healthy rats receiving vehicle; DMF - healthy rats receiving dimethyl fumarate; EAE - rats with experimental allergic encephalomyelitis induced; $E A E+V E H$ - rats with $E A E$ induced, receiving vehicle; $E A E+D M F$ - rats with $\mathrm{EAE}$ induced, receiving DMF.

\section{HO-1 mRNA expression level}

An analysis of the expression level of the mRNA isolated from the brains showed a significantly decreased level of HO-1 mRNA in EAE rats fed with DMF in comparison with EAE non-fed rats, and EAE

rats fed with vehicle animals, on the $10^{\text {th }}$ DPI (Fig. 4A). On the $14^{\text {th }}$ DPI there was a significant drop of mRNA expression in all of the EAE groups of animals compared with the healthy rats fed with DMF (Fig. 4B). On the $21^{\text {st }} \mathrm{DPI}, \mathrm{HO}-1$ mRNA expression was decreased 
in EAE rats, both fed and non-fed, in comparison with healthy rats, fed with vehicle and DMF (Fig. 4C).

\section{Discussion}

Most of the studies on DMF antioxidant activity engaging the Nrf2-dependent pathway, that result in the expression of second phase antioxidant enzymes, are performed on cell cultures in vitro, whereas animal studies tend to focus on showing the influence of DMF on disease progression. In our study, we combined these two aspects of DMF activity by measuring the expression of $\mathrm{HO}-1$ at the mRNA and protein levels in the brains collected from animals with experimental EAE. In our study, we used the MS model with monophasic course, with one relapse and one remission of symptoms, and such a course is characteristic for Lewis rats with experimental EAE. Such monophasic acute EAE may be beneficial for studying innate processes involved in disease development [12]. We also focused on the symptomatic phase of EAE, starting from the $10^{\text {th }} \mathrm{DPI}$, which is the first day of the occurrence of symptoms, the $14^{\text {th }}$ DPI being the day of peak symptoms, and the $21^{\text {st }}$ DPI being the day of remission of symptoms - based on our previous experience using this model of MS [16]. In the present study there was no significant effect of DMF administration to the animals in ameliorating the clinical symptoms - the results only show a tendency, but this is similar to the results obtained by others in DA (Dark Agouti) rats or C57/BL6 mice $[7,29]$. We also noted a very high dispersion of the mean score results, pointing to variation between the animals. We also did not observe any effect of DMF on reduction of body mass decrease; however, the body mass decrease after EAE induction was rather slight.

Our main goal in this study was to analyze the changes in HO-1 expression shown both as the mRNA and protein level during the symptomatic phase of EAE. The results clearly demonstrate that DMF influences HO-1 expression only at the very beginning $\left(10^{\text {th }} \mathrm{DPI}\right)$ and not during the symptomatic phase of the disease $\left(14^{\text {th }} \mathrm{DPI}\right.$ and $\left.21^{\text {st }} \mathrm{DPI}\right)$, pointing to the early engagement of the antioxidant mechanisms induced by DMF in the course of EAE.

Recently, Stojić-Vukanić et al. [34] reported on the effect of DMF in DA rats with induced EAE. Their results showing the clinical score in female rats were consistent with our observations, where the mean score reached a maximum of 1.5 points on a 5 -grade scale. They tested the redox status of the animals, showing that mRNA expression of Nrf2 and HO-1 had increased in the spinal cords collected from rats on the $15^{\text {th }} \mathrm{DPI}$. Also, there was increased activity of one of the Nrf2-regulated enzymes (superoxide dismutase) both in the plasma and the spinal cord. The results of the mRNA expression of HO-1 do not correspond with our results; however, the dose of DMF administered in their study was $100 \mathrm{mg} / \mathrm{kg}$ per day, while up to now, the standard dose used has been $30 \mathrm{mg} / \mathrm{kg}$ per day $[7,23,32]$.

Most of the experiments on the effect of DMF conducted in the animal model of MS, EAE, concern the modification of the activity of immune cells, such as changes in the produced cytokine profiles, cell differentiation, infiltration into the CNS, etc. [11,29,32].

In vitro studies have shed light on the cellular mechanisms involved in the mechanism of action of DMF and also on the regulation of the Nrf2-dependent antioxidant activity of the cells. The studies performed on mammalian (human, rodent) astrocytes have shown that DMF increases the cellular level of the Nrf2 protein and also increases the mRNA expression of the target genes, such as quinone oxidoreductase-1 (NQO-1) [23]. In cultured rat astrocytes, after 6 hours of incubation with lipopolysaccharide and IFN- $\gamma$, there was increased Nrf2 activity and increased HO-1 mRNA expression [22]. The independence of the DMF effect from the Nrf2-dependent pathway was tested in microglia cultures, indicating that cells isolated from $\mathrm{Nrf2}^{-1}$ mice produced decreased levels of proinflammatory cytokines when being treated with DMF [28]. On the other hand, data obtained from murine and human astrocytes treated with DMF, and activated with IL-1 $\beta$, show no significant difference in $\mathrm{HO}-1$ and NQO-1 expression at the mRNA level. Some authors have suggested that the effect of DMF may be cell specific or even Nrf2 independent [10]. Animal studies by Linker et al. [23], showing Nrf2 activation in the chronic phase of EAE induced in mice treated with DMF, revealed increased Nrf2 expression in neurons, oligodendrocytes, and astrocytes, but not in microglia or in T cells, in the spinal cords collected from the animals on the $74^{\text {th }}$ DPI. Such results clearly support the hypothesis of the cellular specificity of Nrf2 activity.

In our experiments we used whole-brain homogenates to analyze the expression of $\mathrm{HO}-1$ at the mRNA 
and protein level. Therefore our results present a unified picture of changes in the CNS, as homogenates contain all cell types present in the particular tissue. We compared the HO-1 expression at the mRNA level to the protein level. Here, we observed that on the $10^{\text {th }}$ DPI the HO-1 mRNA level had decreased in rats with EAE treated with $\mathrm{DMF}$, and the protein level had increased. Also of importance, at the peak of the clinical symptoms (14 $\left.{ }^{\text {th }} \mathrm{DPI}\right)$ and at the time of symptoms remission $\left(21^{\text {st }} \mathrm{DPI}\right)$, there were no changes in the HO-1 expression levels (at either the mRNA or the protein level). This may indicate that in our experiment DMF influenced the course of EAE during the pre-symptomatic phase, and that the last effects were captured on the $10^{\text {th }} \mathrm{DPI}$. The state observed on the $10^{\text {th }} \mathrm{DPI}$, when there was a decreased $\mathrm{HO}-1$ mRNA level and an increased $\mathrm{HO}-1$ protein level, was probably the result of the sequence of events of the process of protein synthesis, beginning with gene transcription, followed by translation and then protein synthesis. At this time point, it is possible that the Nrf2-dependent pathway is no longer influenced by $D M F$, so the transcript (mRNA) level decreases while being used for the following stages of protein synthesis, providing increased levels of protein at that moment. Decreased levels of HO-1 mRNA in all groups of animals with induced EAE, in comparison with healthy animals, on the $14^{\text {th }}$ and $21^{\text {st }}$ DPI may suggest that the Nrf2-dependent pathway is not activated at these particular time points (not only by DMF, but also by oxidative stress accompanying inflammation in the CNS). Studies of MS lesions (derived from autopsies or biopsies of MS patients) show that there is increased Nrf2 expression in active lesions, and that the expression is rather rare in chronic inactive lesions $[21,36]$. Such results, showing the correlation of the activity of the Nrf2-dependent antioxidant pathway with the early phase of disease relapse, confirm the recommendations increasingly made to start MS therapy in patients as soon as there is a suspicion of MS, and not to wait for a confirmed diagnosis $[6,25]$. The MS animal model used in the present study is monophasic EAE, with one peak of symptoms, and remission. In the most common form of MS, i.e., relapsing-remitting MS, there are relapses following remissions. Continuous DMF treatment may be beneficial, as the Nrf2-dependent pathway resulting in $\mathrm{HO}-1$ expression is activated at the very beginning of the relapse, in the pre-symptomatic phase. DMF exerts a bimodal effect in inflammatory neurodegenerative diseases. Firstly, its known anti-inflammatory mode of action prevents the excessive development of the immune response and, secondly, its antioxidant activity protects neurons from oxidative stress leading to degeneration $[1,27,37]$.

In our experiment the expression of $\mathrm{HO}-1$ changed during the course of EAE and the influence of DMF occurred at the pre-symptomatic phase of the disease in experimental animals, hence pointing to the necessity of early therapy in MS patients.

\section{Acknowledgements}

This work was supported by the Ministry of Higher Education Fund for Young Researchers, Grant No. 1MA/PM11/15.

\section{Disclosure}

Authors report no conflict of interest.

\section{References}

1. Albrecht P, Bouchachia I, Goebels N, Henke N, Hofstetter HH, Issberner A, Kovacs Z, Lewerenz J, Lisak D, Maher P, Mausberg AK, Quasthoff K, Zimmermann C, Hartung HP, Methner A. Effects of dimethyl fumarate on neuroprotection and immunomodulation. J Neuroinflammation 2012; 9: 163.

2. Bénardais K, Pul R, Singh V, Skripuletz T, Lee DH, Linker RA, Gudi V, Stangel $M$. Effect of fumaric acid esters on blood-brain barrier tight junction proteins. Neurosci Lett 2013; 555: 165-170.

3. Cada DJ, Levien TL, Baker DE. Formulary Drug Reviews. Dimethyl Fumarate. Hosp Pharm 2013; 48: 668-679.

4. Cardozo LF, Pedruzzi LM, Stenvinkel P, Stockler-Pinto MB, Daleprane JB, Leite M Jr, Mafra D. Nutritional strategies to modulate inflammation and oxidative stress pathways via activation of the master antioxidant switch Nrf2. Biochmie 2013; 95: 1525-1533.

5. Castro-Borrero W, Graves D, Frohman TC, Flores AB, Hardeman P, Logan D, Orchard M, Greenberg B, Frohman EM. Current and emerging therapies in multiple sclerosis: a systematic review. Ther Adv Neurol Disord 2012; 5: 205-220.

6. Comi G, Martinelli V, Rodegher M, Moiola L, Leocani L, Bajenaru O, Carra A, Elovaara I, Fazekas F, Hartung HP, Hillert J, King J, Komoly S, Lubetzki C, Montalban X, Myhr KM, Preziosa P, Ravnborg M, Rieckmann P, Rocca MA, Wynn D, Young C, Filippi M. Effects of early treatment with glatiramer acetate in patients with clinically isolated syndrome. Mult Scler 2013; 19: 1074-1083.

7. de Bruin NM, Schmitz K, Schiffmann S, Tafferner N, Schmidt M, Jordan H, Häußler A, Tegeder I, Geisslinger G, Parnham MJ. Multiple rodent models and behavioral measures reveal unexpected responses to FTY720 and DMF in experimental autoimmune encephalomyelitis. Behav Brain Res 2016; 300: 160-174.

8. de Jong R, Bezemer AC, Zomerdijk TP, van de Pouw-Kraan T, Ottenhoff $\mathrm{TH}$, Nibbering $\mathrm{TH}$. Selective stimulation of $\mathrm{T}$ helper 2 cytokine 
responses by the anti-psoriasis agent monomethylfumarate. Eur J Immunol 1996; 26: 2067-2074.

9. di Nuzzo L, Orlando R, Nasca C, Nicoletti F. Molecular pharmacodynamics of new oral drugs used in the treatment of multiple sclerosis. Drug Des Devel Ther 2014; 8: 555-568.

10. Galloway DA, Williams JB, Moore CS. Effects of fumarates on inflammatory human astrocyte responses and oligodendrocyte differentiation. Ann Clin TransI Neurol 2017; 4: 381-391.

11. Ghoreschi K, Brück J, Kellerer C, Deng C, Peng H, Rothfuss O, Hussain RZ, Gocke AR, Respa A, Glocova I, Valtcheva N, Alexander E, Feil S, Feil R, Schulze-Osthoff K, Rupec RA, Lovett-Racke AE, Dringen R, Racke MK, Röcken M. Fumarates improve psoriasis and multiple sclerosis by inducing type II dendritic cells. J Exp Med 2011; 208: 2291-2303.

12. Gold R, Linington C, Lassmann $\mathrm{H}$. Understanding pathogenesis and therapy of multiple sclerosis via animal models: 70 years of merits and culprits in experimental autoimmune encephalomyelitis research. Brain 2006; 129: 1953-1971.

13. Höxtermann S, Nüchel C, Altmeyer P. Fumaric acid esters suppress peripheral CD4- and CD8- positive lymphocytes in psoriasis. Dermatology 1998; 196: 223-230.

14. Itoh K, Chiba T, Takahashi S, Ishii T, Igarashi K, Katoh Y, Oyake T, Hayashi N, Satoh K, Hatayama I, Yamamoto M, Nebeshima Y. An Nrf2/Small Maf heterodimer mediates the induction of phase II detoxifying enzyme genes through antioxidant response elements. Biochem Biophys Res Commun 1997; 236: 313-322.

15. Kappos L, Freedman MS, Polman CH, Edan G, Hartung HP, Miller DH, Montalbán X, Barkhof F, Radü EW, Metzig C, Bauer L Lanius V, Sandbrink R, Pohl C; BENEFIT Study Group. Long-term effect of early treatment with interferon beta-1b after a first clinical event suggestive of multiple sclerosis: 5-year active treatment extension of the phase 3 BENEFIT trial. Lancet Neurol 2009; 8: 987 997.

16. Kasarello K, Kwiatkowska-Patzer B, Lipkowski AW, Bardowski JK, Szczepankowska AK. Oral administration of lactococcus lactis expressing synthetic genes of myelin antigens in decreasing experimental autoimmune encephalomyelitis in rats. Med Sci Monit 2015; 21; 1587-1597.

17. Keum YS. Regulation of the Keap1/Nrf2 system by chemopreventive sulforaphane: implications of posttranslational modifications. Ann N Y Acad Sci 2011; 1229: 184-189.

18. Kwiatkowska-Patzer B, Michałkiewicz J, Kubiszewska I, Zielińska J, Kasarello K, Kurzepa K, Lipkowski AW. Spinal cord hydrolysate ameliorate immunological reaction in experimental allergic encephalomyelitis. Acta Neurobiol Exp (Wars) 2009; 69: 73-78.

19. Lassmann $\mathrm{H}$, van Horssen J, Mahad D. Progressive multiple sclerosis: pathology and pathogenesis. Nat Rev Neurol 2012; 8: 647-656.

20. Lassmann H. Multiple sclerosis: lessons from molecular neuropathology. Exp Neurol 2014; 262 Pt A:2-7.

21. Licht-Mayer S, Wimmer I, Traffehn S, Metz I, Brück W, Bauer J, Bradl M, Lassmann H. Cell type-specific Nrf2 expression in multiple sclerosis lesions. Acta Neuropathol 2015; 130: 263-277.

22. Lin SX, Lisi L, Dello Russo C, Polak PE, Sharp A, Weinberg G, Kalinin S, Feinstein DL The anti-inflammatory effects of dimethyl fumarate in astrocytes involve glutathione and haem oxygenase-1. ASN Neuro 2011; 3; doi: 10.1042/AN20100033.
23. Linker RA, Lee DH, Ryan S, van Dam AM, Conrad R, Bista P, Zeng W, Hronowsky X, Buko A, Chollate S, Ellrichmann G, Brück W, Dawson K, Goelz S, Wiese S, Scannevin RH, Lukashev M, Gold R. Fumaric acid esters exert neuroprotective effects in neuroinflammation via activation of the Nrf2 antioxidant pathway. Brain 2011; 134: 678-692.

24. Linker RA, Gold R. Dimethyl fumarate for treatment of multiple sclerosis: mechanism of action, effectiveness, and side effects. Curr Neurol Neurosci Rep 2013; 13: 394.

25. Merkel B, Butzkueven H, Traboulsee AL, Havrdova E, Kalincik T. Timing of high-efficacy therapy in relapsing-remitting multiple sclerosis: A systematic review. Autoimmun Rev 2017; 16: 658-665.

26. Nicholas JA, Boster AL, Imitola J, O'Connell C, Racke MK. Design of oral agents for the management of multiple sclerosis: benefit and risk assessment for dimethyl fumarate. Drug Des Devel Ther 2014; 8: 897-908.

27. Ohl K, Tenbrock K, Kipp M. Oxidative stress in multiple sclerosis: Central and peripheral mode of action. Exp Neurol 2016; 277: 58-67.

28. Peng H, Li H, Sheehy A, Cullen P, Allaire N, Scannevin RH. Dimethyl fumarate alters microglia phenotype and protects neurons against proinflammatory toxic microenvironments. J Neuroimmunol 2016; 299: 35-44.

29. Reick C, Ellrichmann G, Thöne J, Scannevin RH, Saft C, Linker RA, Gold R. Neuroprotective dimethyl fumarate synergizes with immunomodulatory interferon beta to provide enhanced axon protection in autoimmune neuroinflammation. Exp Neurol 2014; 257: 50-56.

30. Satoh T, McKercher SR, Lipton SA. Reprint of: Nrf2/ARE-mediated antioxidant actions of pro-electrophilic drugs. Free Radic Biol Med 2014; 66: 45-57.

31. Scannevin RH, Chollate S, Jung M, Shackett M, Patel H, Bista P, Zeng W, Ryan S, Yamamoto M, Lukashev M, Rhodes KJ. Fumarates promote cytoprotection of central nervous system cells against oxidative stress via the nuclear factor (erythroid-derived 2)-like 2 pathway. J Pharmacol Exp Ther 2012; 341: 274-284.

32. Schilling S, Goelz S, Linker R, Luehder F, Gold R. Fumaric acid esters are effective in chronic experimental autoimmune encephalomyelitis and suppress macrophage infiltration. Clin Exp Immunol 2006; 145: 101-107.

33. Sospedra M, Martin R. Immunology of Multiple Sclerosis. Annu Rev Immunol 2005; 23: 683-747.

34. Stojić-Vukanić Z, Kotur-Stevuljević J, Nacka-Aleksić M, Kosec D, Vujnović I, Pilipović I, Dimitrijević M, Leposavić G. Sex Bias in Pathogenesis of Autoimmune Neuroinflammation: Relevance for Dimethyl Fumarate Immunomodulatory/Anti-oxidant Action. Mol Neurobiol 2017; doi: 10.1007/s12035-017-0595-2.

35. Treumer F, Zhu K, Gläser R, Mrowietz U. Dimethylfumarate is a potent inducer of apoptosis in human T cells. I Invest Dermatol 2003; 121: 1383-1388.

36. van Horssen J, Drexhage JA, Flor T, Gerritsen W, van der Valk P, de Vries HE. Nrf2 and DJ1 are consistently upregulated in inflammatory multiple sclerosis lesions. Free Radic Biol Med 2010; 49: 12831289.

37. Wilms H, Sievers J, Rickert U, Rostami-Yazdi M, Mrowietz U, Lucius R. Dimethylfumarate inhibits microglial and astrocytic inflammation by suppressing the synthesis of nitric oxide, IL-1beta, TNF-alpha and IL-6 in an in-vitro model of brain inflammation. J Neuroinflammation 2010; 7: 30 